\section{Facing the Challenges of the Twenty-First Century}

\section{Jamil Salmi}

Jamil Salmi is education sector manager, Latin America and the Caribbean Region at the World Bank. Address: World Bank, 1818 H St., NW, Washington, DC 20433. USA.

It is not the strongest species that survive, nor the most intelligent, but the ones most responsive to change. -Charles Darwin

$\mathrm{I}_{\mathrm{I}}^{\mathrm{n}}$ magine a university without classrooms or even a library. Imagine a university 10,000 miles away from its students. Imagine a university without required courses or majors or grades. Imagine a degree only valid for five years. Imagine ranking institutions by their degree of Internet connectivity. Imagine a country whose main export earnings came from the sale of higher education services. Imagine a socialist country that charged full-cost tuition fees in public higher education. Are these science fiction images or real-life stories of a revolution in higher education?

In the past few years, many countries have witnessed significant transformations in their higher education systems. But the tertiary education landscape is not changing as fast everywhere. The oldest university on the American continent, the Autonomous University of Santo Domingo in the Dominican Republic, is about to collapse under the pressure of its 80,000 students, who are crowded into facilities designed for 6,000 students. In this rapidly evolving world, what is likely to happen to higher education institutions unable to change?

\section{The Challenges to Higher Education}

At the turn of the 21 st century, three major challenges confront higher education: economic globalization, the growing importance of knowledge, and the information and communication revolution. These trends herald radical changes in a number of areas. First, a trend toward higher skills has been observed in OECD (Organisation for Economic Cooperation and Development) countries and in the most-advanced developing countries. This is illustrated by recent data from Argentina, Brazil, and Mexico showing a rising rate of return for tertiary education-a reversal of earlier trends in the 1980s.

Continuing education is growing in importance because of the necessity to update knowledge and skills regularly. The traditional approach of getting a degree before starting one's professional life is being progressively replaced by lifelong education. The traditional structure of the university as a pyramid with a majority of first-degree students and a smaller group of graduate students will be replaced by an inverted pyramid with a minority of firsttime students, a larger group of students pursuing a sec- ond or third degree, and a majority of students enrolled in short-term continuing education.

The acceleration of technical progress has reduced the emphasis on the acquisition of factual knowledge per se and, at the same time, the increased importance of methodological knowledge and skills (i.e., the ability to learn in an autonomous manner). In many disciplines, factual knowledge taught in the first year may become obsolete before graduation. In this new paradigm, learning to learn is more important than memorizing specific information, and primacy is given to analytical skills and the ability to find information.

A related development is the increasing attractiveness of university degrees with an international application. In the United States, a rapidly growing number of on-line universities are reaching out to students in foreign countries. Jones International University, which already serves students in 38 countries, is the first on-line university in the world to be formally accredited. The Technology Institute of Monterey has established a virtual university with branches throughout Mexico and Latin America. Asia and Eastern Europe have seen a proliferation of "overseas validated courses" offered by franchise institutions representing British and Australian universities.

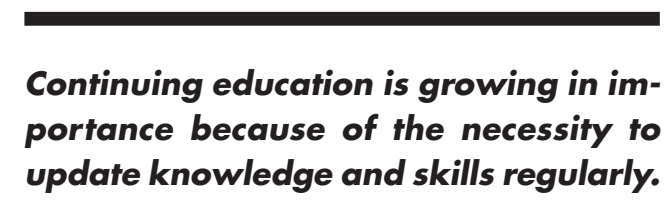

The best universities of any country can reach out across borders by means of the Internet or satellites, effectively competing with any national university on its own territory. The California-based University of Phoenix, one of the most dynamic new distance universities in the United States, already boasts an enrollment of 68,000 students. In the United States alone, there are already more than 3,000 institutions offering on-line training. Corporate universities, of which there are about 1,000 in operation, are another form of competition.

The emergence of these new forms of competition is likely to change the nature of quality assurance. At the institutional level, it is doubtful that the principles and standards to evaluate campus-based programs can be used to assess the quality of on-line courses without significant adjustments. At the national level, countries need to develop information systems and participate in international networks to be able to evaluate the quality of the foreign programs available to their students.

New training needs and competitive challenges will require many universities to transform their governance, 
structure, and mode of operation. A key aspect is the ability to reorganize traditional disciplines, taking into consideration the emergence of new scientific and technological fields, such as biotechnology and advanced materials science, that require the creation of inter- and multidisciplinary programs across traditional institutional barriers. For example, the study of molecular devices and sensors brings together specialists in electronics, materials science, chemistry, and biology.

\section{The challenges of globalization, knowl- edge-based economic growth, and the information and communications revo- lution can be seen either as terrible threats or as tremendous opportunities.}

The use of modern technology has just begun to revolutionize the way learning occurs. The use of multimedia together with computers permits the development of interactive pedagogical approaches. In Brazil, a few schools of medicine and engineering have been experimenting with the use of computer-based programs to teach mathematics, resulting in a decrease in dropout rates from 70 to 30 percent.

The information revolution will have far-reaching implications for how universities are organized and ranked. A May 1999 article ("America's 100 Most Wired Colleges") in Yahoo! Internet Life reported the results of a recent survey that assessed U.S. universities on the basis of their computer and communication infrastructure and their level of Internet use for pedagogical and administrative purposes. But university leaders must keep in mind the high cost of information technology, not only the initial capital investment but also the recurrent budget needed for maintaining the infrastructure.

Increasingly, tertiary education institutions will need the flexibility to react swiftly to establish new programs, reconfigure existing ones, and eliminate outdated programs. Effective feedback mechanisms, such as tracer surveys and regular consultation with employers and alumni, are indispensable for this purpose. But in many countries, universities follow very rigid procedures. In Uruguay, only when confronted with competition from new private universities did the venerable University of the Republic consider establishing graduate programs for the first time.

\section{Conclusion}

The challenges of globalization, knowledge-based economic growth, and the information and communications revolution can be seen either as terrible threats or as tremendous opportunities. Countries and higher education institutions willing to take advantage of these new opportunities must actively launch meaningful reforms and innovations. While there is no one blueprint for all, a common prerequisite may be to formulate a clear vision of how the higher education system can effectively contribute to national development and how each institution should evolve within that system.

A final word of caution is warranted to signal the danger of focusing exclusively on technical progress and globalization. Adapting to the changing environment is not only about reshaping tertiary institutions and applying new technologies. It is equally vital to ensure that students are equipped with the core values necessary to live in complex democratic societies.

Author's Note: The findings, interpretations, and conclusions expressed in this paper are entirely those of the author and should not be attributed in any manner to the World Bank.

World Bank Report on "Higher Education in Developing Countries" Released

Higher Education in Developing Countries: Peril and Promise has just been published by the Task Force on Higher Eduation and Society, in cooperation with the World Bank. The report, prepared by a blue ribbon panel of experts, focuses on the challenges faced by higher education in developing countries. The task force members examine such central issues as higher education and the public interest, the role of systems of higher education, governance, science and technology, and general education. Co-chairs Mamphela Ramphele of South Africa and Henry Rosovsky of the United States have stressed that they wanted to provide a fresh perspective in the report. In addition to the narrative, a number of "best practice" examples are provided and useful statistical appendices are included as well.

The Task Force and the World Bank are providing copies of the report to many of the readers of International Higher Education. Copies will be sent to a selection of names on our mailing list. In addition, the report is available from the World Bank's Bookshop, $1818 \mathrm{H}$ St., NW, Washington, DC 29433, USA. It is also avaialble in full-text on the Internet. The Web site is: $<$ http://www.tfhe.net>.

The specific citation to the report is: Task Force on Higher Education and Society, Higher Education in Developing Countries: Peril and Promise. Washington, D.C.: The World Bank, 2000. 135 pp (paperback). ISBN 08213-4630-X. 